Check for updates

Cite this: RSC Adv., 2017, 7, 36021

Received 29th May 2017

Accepted 12th July 2017

DOI: 10.1039/c7ra05925f

rsc.li/rsc-advances

\section{Highly efficient FRET from aggregation-induced emission to BODIPY emission based on host-guest interaction for mimicking the light-harvesting system $\dagger$}

\author{
Shuai Wang, ${ }^{a}$ Jia-Hai Ye, (D) *a Zhong Han, ${ }^{\mathrm{b}}$ Zheng Fan, ${ }^{a}$ Caijiang Wang, ${ }^{\text {a }}$ Cancan Mu, ${ }^{a}$ \\ Wenchao Zhang (D) ${ }^{a}$ and Weijiang $\mathrm{He}$ (D)*b
}

A novel fluorescence resonance energy transfer (FRET) system based on the interaction of an AIE luminogen (tetraphenylethene, TPE) and BODIPY derivative as the host and guest, respectively, was disclosed. This FRET system worked well for mimicking a light harvesting system with highly energy transfer efficiency up to $93 \%$ from aggregation-induced emission to BODIPY emission and shows excellent tolerance to acidic and basic environments.
Fluorescence resonance energy transfer (FRET) is a photophysical process through which an electronically excited fluorescent "donor" molecule transfers its excitation energy to an "acceptor" molecule nonradiatively through a long-range dipole-dipole interaction. ${ }^{1,2}$ FRET is widely studied and proved to be a powerful spectroscopic technique to accurately measure the distance between two fluorescent sources at the nanometer scale, ${ }^{3,4}$ enabling the study of molecular conformations $^{5}$ and interaction dynamics. ${ }^{6}$ Moreover, FRET is a core phenomenon in photosynthesis, ${ }^{7,8}$ organic photovoltaics, ${ }^{9}$ lighting sources, ${ }^{10,11}$ biosensing, ${ }^{12-14}$ or drug delivery tracing. ${ }^{15}$ Furthermore, for practical applications, two requirements are necessary for the FRET process to occur: (1) a substantial overlap of the donor emission spectrum with the acceptor absorption; (2) an appropriate linker and distance between the donor and the acceptor. ${ }^{16}$

The light-harvesting system, which collects sunlight efficiently and funnels the excitation energy to the reaction center, which converting solar to chemical energy, plays a very important role in natural photosynthesis. ${ }^{17}$ Many artificial lightharvesting molecules are synthesized in succession. ${ }^{18}$ An ideal light-harvesting system absorbs light efficiently in a relatively broad region covering most of the sunlight spectrum and carries the energy smoothly to the reaction center. In order to achieve this for mimicking the light-harvesting system, the

${ }^{a}$ School of Chemical Engineering, Nanjing University of Science and Technology, Nanjing 210094, P. R. China. E-mail: yejiahai@njust.edu.cn; Fax: +86 258431 5857; Tel: +862584303116

${ }^{b}$ State Key Laboratory of Coordination Chemistry, School of Chemistry and Chemical Engineering, Nanjing University, Nanjing 210093, P. R. China. E-mail: heweij69@nju. edu.cn; Fax: +86258331 4502; Tel: +862583597066

$\uparrow$ Electronic supplementary information (ESI) available. See DOI: $10.1039 / \mathrm{c} 7 \mathrm{ra} 05925 \mathrm{f}$ integration of multiple excellent chromophores or fluorophores is necessary based on FRET process. With the broad field of FRET applications at hand, the impressive progress of mimicking the photosynthetic light-harvesting system with synthetic models, which is significantly meaningful not only for our understanding of the function and mechanism of photosynthesis but also in the development of potential applications in terms of organic light-emitting diodes (OLED), ${ }^{19}$ dyesensitized solar cells (DSSC), ${ }^{19 a, 20}$ and other optoelectronic devices, ${ }^{21}$ offers appealing opportunities to enhance FRET and extend its versatility and is currently attracting increasing interest from biologists and chemists.

So far, lots of covalent and non-covalent artificial lightharvesting systems based on FRET have been developed, most of which were constructed by fluorescent donor-acceptor models. ${ }^{22}$ Recently, with the rapid development of supramolecular chemistry, more and more efforts were contributed towards developing the non-covalent artificial light-harvesting systems, and among them crown ethers, ${ }^{23}$ cyclodextrins,${ }^{24}$ pillararenes, ${ }^{25}$ and host-guest complexes containing multiple hydrogen bonds ${ }^{23,26}$ were frequently employed as building scaffolds.

It was well-known that most conventional luminophores such as the fluorescent donor and acceptor in host-guest systems with strong luminescence in solution become weakly emissive or nonemissive in the aggregate or solid state due to the notorious aggregation-caused quenching (ACQ), ${ }^{27}$ which has greatly limited the applications of luminescent materials. To overcome the drawback of ACQ, Tang et al. developed an effective methodology named aggregation-induced emission (AIE) which has drawn increasing research interest as the opposite of ACQ systems. ${ }^{27 a, 28}$ Because of their exactly opposite luminescent behaviours, AIE and ACQ materials are not easily 
coupled to construct new efficient luminescent materials. Recently, some attempts to combine AIE and ACQ luminophores by covalent bonding were made, ${ }^{29}$ but they failed in realising the advantages of combining both classes of dye. The development of a feasible approach for achieving the effective collaboration of AIE and ACQ luminophores and constructing highly efficient FRET-based light-harvesting materials for practical applications remains an important challenge.

Herein, we introduce an efficient strategy to achieve the coupling of AIE and ACQ chromophores via FRET for the construction of high-efficiency light-harvesting system. As a prototypical AIE luminogen (AIEgen), tetraphenylethene (TPE) was chosen to combine with crown ether moieties as a host and energy donor in FRET system. Meanwhile, due to their outstanding and desirable properties such as high absorption coefficients, sharp emissions, high fluorescence quantum yields, and excellent chemical and photostability, borondipyrromethene (BODIPY) dyes were chosen as the chromophores in light-harvesting systems. ${ }^{25,30}$ We prepared a borondipyrromethene (BODIPY) derivative containing benzylamino group as the guest and energy acceptor (Scheme 1). The details of syntheses of the host and guest compounds can be found in the Fig. S1 and S2 (ESI $\dagger$ ). The target host compound M1 was prepared from dimethyl TPE and dibenzo[24]-crown-8 (DB24C8). The target guest compound M2 was prepared from BODIPY derivative after several steps. The chemical structures of the target compounds were fully characterized by ${ }^{1} \mathrm{H} \mathrm{NMR}$, ${ }^{13} \mathrm{C}$ NMR, and MS (ESI $\dagger$ ).

AIEgen TPE derivatives such as M1 becomes highly emissive in the aggregate state with the gradual increasing of the fraction of the poor solvent (Fig. S3, ESI $\dagger$ ). But usually the traditional ACQ luminophores turn to be none or weakly fluorescence emissive under this condition. Numerous endeavors can be made to prevent or alleviate the ACQ problem, including the introduction of bulky substituents, ${ }^{31}$ enhanced intramolecular charge transfer (ICT) transition, ${ }^{32}$ cross-dipole packing, ${ }^{33}$ and Jaggregated formation. ${ }^{34}$ With the molecular structure of guest $\mathbf{M} 2$ in hand, we try to obtain the fluorescence behaviour of M2

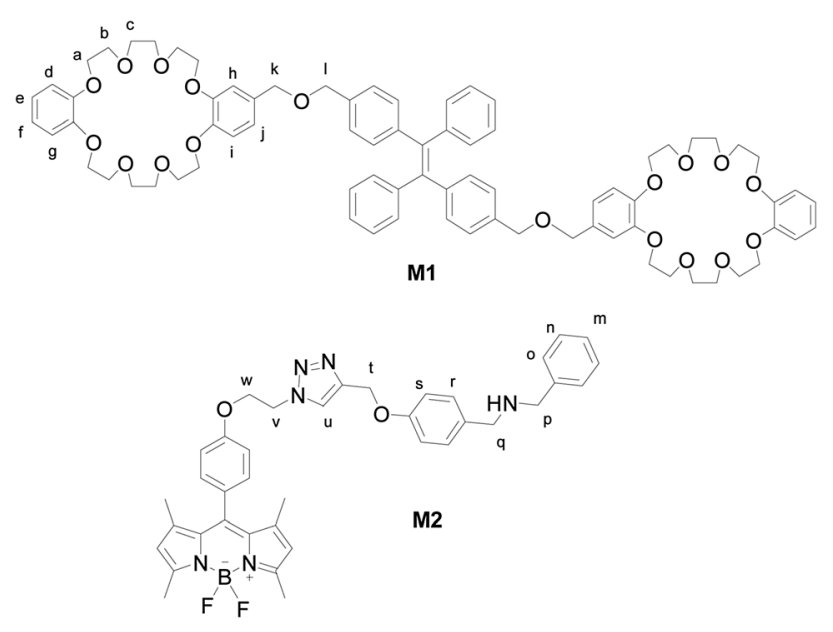

Scheme 1 FRET donor (host) M1 and acceptor (guest) M2. in pure organic solvent (THF) and the solution with the increasing addition of the poor solvent. As expected, no remarkable emission intensity of $\mathbf{M} 2$ at $510 \mathrm{~nm}$ was observed upon the addition of water, even up to $90 \%$ fraction of water (Fig. S4(d), ESI $\dagger$ ).

As shown in Fig. S4(e) (ESI $\dagger$ ), the recording of the absorption and AIE emission spectra for guest M2 and host M1 verified them as the appreciable combinatorial duo to establish the FRET system, where the emission range of donor TPE (400-570 $\mathrm{nm}$ ) almost coincided with the absorption range of acceptor BODIPY (430-530 nm). Furthermore, the maximum excitation wavelength of $\mathbf{M} 2$ was determined as $475 \mathrm{~nm}$, which is consistent with AIE emission wavelength of M1, suggesting the occurrence of FRET.

In order to investigate the complexation of host with guest in solution, the fluorescence titration experiments were first performed to monitor the AIE emission at $465 \mathrm{~nm}$ corresponding to M1 and emission at $515 \mathrm{~nm}$ for M2 by adding increasing amount of guest $\mathbf{M} 2$ into the solution (THF : $\mathrm{H}_{2} \mathrm{O}, 2: 8, \mathrm{v} / \mathrm{v}$ ) of host M1. As shown as in Fig. 1 and S6 (ESI $\dagger$ ), with gradual addition of M2, the AIE emission peak of M1 at $465 \mathrm{~nm}$ decreased gradually, while the emission peak of $\mathbf{M} 2$ at $510 \mathrm{~nm}$ appeared and then increased remarkably, indicating the formation of a new complex between M1 and M2. When more than 0.30 equiv. of $\mathbf{M} 2$ was added to the $\mathbf{M 1}$ solution, the fluorescence intensities at both $480 \mathrm{~nm}$ and $510 \mathrm{~nm}$ showed almost no change. Moreover, the change in fluorescence emission colour before and after the addition of the guest could be easily distinguished by the naked eye (Fig. S7, ESI $\dagger$ ). The above results clearly demonstrated that an efficient FRET effect from donor M1 to acceptor M2 existed in the host-guest complex. From the fluorescence titration result, the FRET efficiency was further calculated to be $93 \%$ for the host-guest system. In order to get more evidence for interaction of host and guest, the TEM images were performed. As shown in Fig. 2, the nanoparticle of spherical morphology of host M1 in aggregation state turn to prismatic crystal after the addition of guest M2, which directly representing the host-guest recognition occurred and resulted in the formation of complex system to generate FRET.

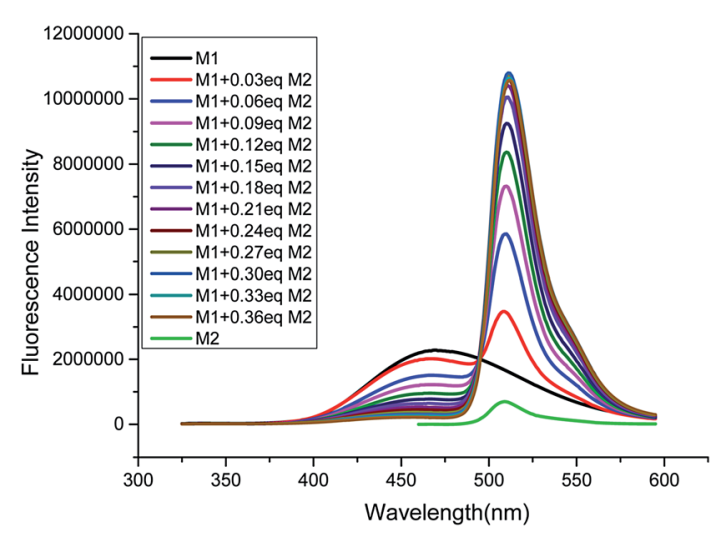

Fig. 1 Fluorescence titration spectra of compound M1 (10 $\mu \mathrm{M})$ towards $M 2(0,0.03,0.06,0.09,0.12,0.15,0.18,0.21,0.24,0.27,0.30$, $0.33,0.36$ equiv.) in $\mathrm{THF} / \mathrm{H}_{2} \mathrm{O}(1: 9, \mathrm{v} / \mathrm{v})$ medium $\left(\lambda_{\text {ex }}: 305 \mathrm{~nm}\right)$. 


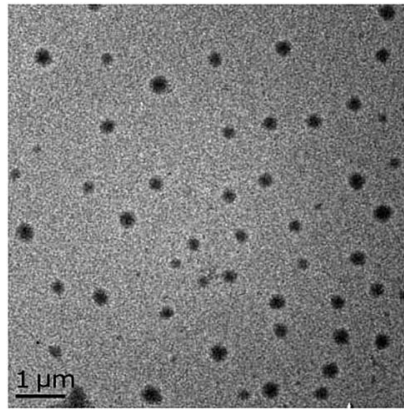

(a)

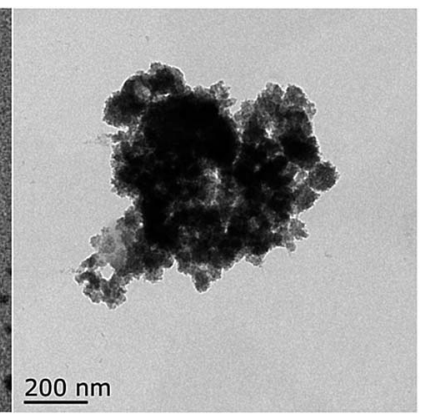

(b)
Fig. 2 (a) Imagine of $M 1(10 \mu M)$ in TEM at $1000 \mathrm{~nm}$, (b) imagine of M1 $(10 \mu \mathrm{M})$ upon addition of M2 (0.3 equiv.) in TEM at $200 \mathrm{~nm}$.

To gain further understanding the pH-responsibility of the observed FRET phenomenon, we monitored the fluorescence changes upon adding acid and base into the THF/water solution containing $\mathbf{M} 1$ and $\mathbf{M} 2$ in a $1: 1$ mole ratio. The pH-responsive titration was performed by the addition of $\mathrm{CF}_{3} \mathrm{COOH}$ and $\mathrm{DBU}$ to the host/guest complex solution gradually to adjust the $\mathrm{pH}$ value of the solution. To our surprise, no obvious changes of the fluorescence emission intensities of the FRET system under acid and base condition were observed. Moreover, the fluorescence emission intensity of the FRET upon the $\mathrm{K}^{+}$addition also did not change remarkably. Furthermore, the absorbance of M1 and $\mathbf{M} 2$ in aggregation state was obtained (Fig. S4(b), ESI $\dagger$ ). This FRET system absorbs light efficiently in broad region covering most of the sunlight spectrum $(200-550 \mathrm{~nm})$. The above results indicated that this complex of M1 and $\mathbf{M} 2$ was a highly efficient and pH stable FRET system for mimicking very stable lightharvesting system. Under acidic condition, the interaction of crown ether in host with dibenzylammonium salt in guest occurred. After the addition of base, the interaction of host and guest was changed to the interaction of crown ether with trizole unit and the distances between donor and acceptor chromophores or fluorophores changed slightly, so this complex of M1 and M2 shows $\mathrm{pH}$ stable FRET property.

The host-guest interaction between donor and acceptor was investigated by ${ }^{1} \mathrm{H}$ NMR to obtain important insights into the complexation behavior of M1 with $\mathbf{M 2}$ in aggregation state (Fig. 3). After the addition of acceptor $\mathbf{M 2}$ to donor M1, the slight changes in the chemical shifts of the protons $\mathrm{H}_{\mathrm{a}}$ (from 4.190 to $4.192 \mathrm{ppm}$ ), $\mathrm{H}_{\mathrm{b}}$ (from 3.941 to $3.945 \mathrm{ppm}$ ), $\mathrm{H}_{\mathrm{c}}$ (from 3.842 to $3.860 \mathrm{ppm}$ ), and the benzyl protons $\mathrm{H}_{\mathrm{k}}$ and $\mathrm{H}_{\mathrm{l}}$ (from 4.452 to $4.453 \mathrm{ppm}$ ) in the crown ether units were observed by comparison of the ${ }^{1} \mathrm{H}$ NMR spectra of M1 and the mixture. The multiplet and doublet peaks at 6.877-6.929 ppm corresponds to the aromatic protons $\mathrm{H}_{\mathrm{d}}-\mathrm{H}_{\mathrm{j}}$ of crown ether units turn into sharp peaks. This result indicated the occurrence of host-guest interactions between donor M1 and acceptor M2, which agreed with the FRET behaviour of host-guest system. Furthermore, the ${ }^{1} \mathrm{H}$ NMR titration under acid and base conditions was also carried out. Upon the addition of two equivalent of $\mathrm{CF}_{3} \mathrm{COOH}$ to the solution of M1 and M2, obvious changes in the chemical shift were observed. Upfield shifts were observed for cyclohexylmethylene protons $\mathrm{H}_{\mathrm{b}}$ (from 3.945 to $3.873 \mathrm{ppm}$ ), and $\mathrm{H}_{\mathrm{c}}$

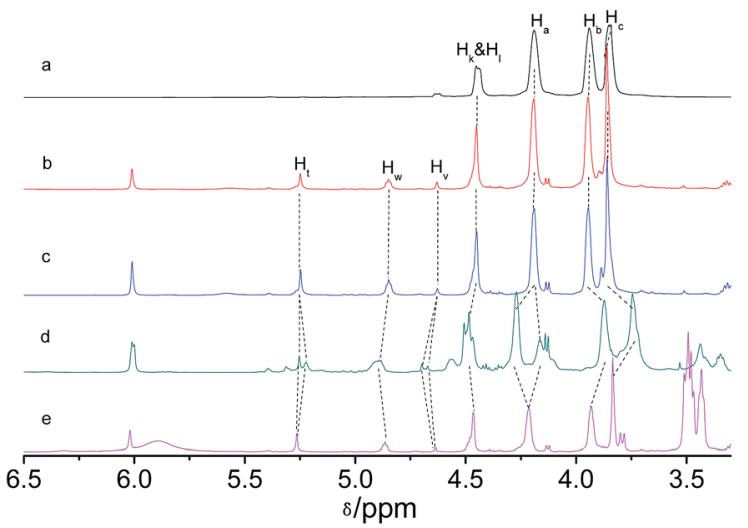

(1)

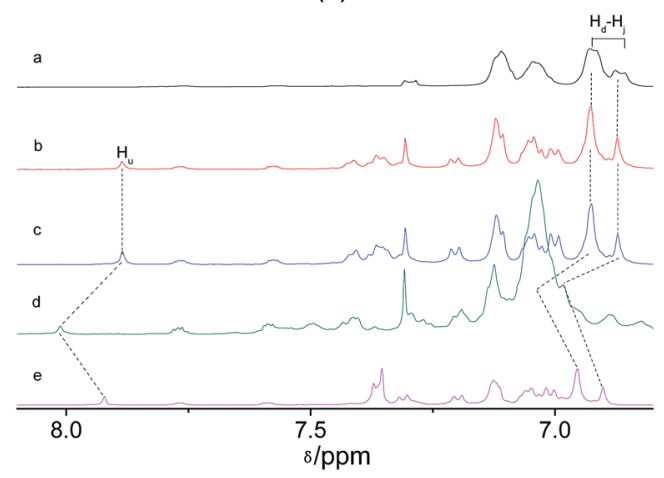

(2)

Fig. 3 Partial ${ }^{1} \mathrm{H}$ NMR spectra $\left(500 \mathrm{MHz}, \mathrm{CDCl}_{3}\right)$ : (a) ${ }^{1} \mathrm{H}$ NMR spectrum of host M1 (1.0 mM), (b) ${ }^{1} \mathrm{H}$ NMR spectrum of host $\mathrm{M} 1$ (1.0 mM) upon addition of 0.5 equiv. of guest $M 2$, (c) ${ }^{1} \mathrm{H} N M R$ spectrum of host M1 (1.0 $\mathrm{mM}$ ) upon addition of 1.0 equiv. of guest $\mathrm{M} 2$ in $\mathrm{CDCl}_{3}$, (d) ${ }^{1} \mathrm{H} \mathrm{NMR}$ spectrum of host-guest system in (b) upon addition of 2.0 equiv. of $\mathrm{CF}_{3} \mathrm{COOH}$, (e) ${ }^{1} \mathrm{H}$ NMR spectrum of host-guest system in (c) upon addition of 4.0 equiv. of DBU.

(from 3.860 to $3.745 \mathrm{ppm}$ ), but the signal peak corresponding to proton $\mathrm{H}_{\mathrm{a}}$ splits into two sets of signals, one upshift from 4.192 to $4.165 \mathrm{ppm}$ while another downshift from 4.192 to 4.271 . Downfield shifts were also observed for the benzyl protons $\mathrm{H}_{\mathrm{k}}$ and $\mathrm{H}_{1}$ (from 4.453 to $4.485 \mathrm{ppm}$ ) in host M1. Moreover, downfield shifts was observed for the protons $\mathrm{H}_{\mathrm{v}}$ (from 4.626 to $4.686 \mathrm{ppm}$ ) and $\mathrm{H}_{\mathrm{w}}$ (from 4.848 to $4.893 \mathrm{ppm}$ ) in $\mathrm{CH}_{2} \mathrm{CH}_{2}$ unit of guest M2. Most important, the remarkable downfield shift was observed for the vinyl proton $\mathrm{H}_{\mathrm{u}}$ (from 7.885 to $8.012 \mathrm{ppm}$ ) in trizole unit of guest M2. Subsequently, upon the addition of four equivalent of base DBU to the previous solution of $\mathbf{M 1}$ and M2, downfield shifts were observed for the protons $\mathrm{H}_{b}, \mathrm{H}_{\mathrm{c}}$ and $H_{t}$, meanwhile, upshifts were observed for the protons $H_{b}, H_{c}$, $\mathrm{H}_{\mathrm{k}}, \mathrm{H}_{\mathrm{l}}, \mathrm{H}_{\mathrm{v}}, \mathrm{H}_{\mathrm{w}}$, and $\mathrm{H}_{\mathrm{u}}$ etc. (Fig. S14, ESI $\dagger$ ). Based on the combination of the results of FRET titration and ${ }^{1} \mathrm{H}$ NMR titration, the plausible interaction mechanism of the host and guest was proposed as in Scheme 2. Under the acid condition, the recognition of crown ether to occurred. After the enough base addition, the crown ether switch from dibenzylammonium salt to chain unit near BODIPY core.

In conclusion, a new AIE fluorescence donor constructed by TPE with DB24C8 and a new fluorescence acceptor constructed by BODIPY with dibenzylamine linked with trizole were 


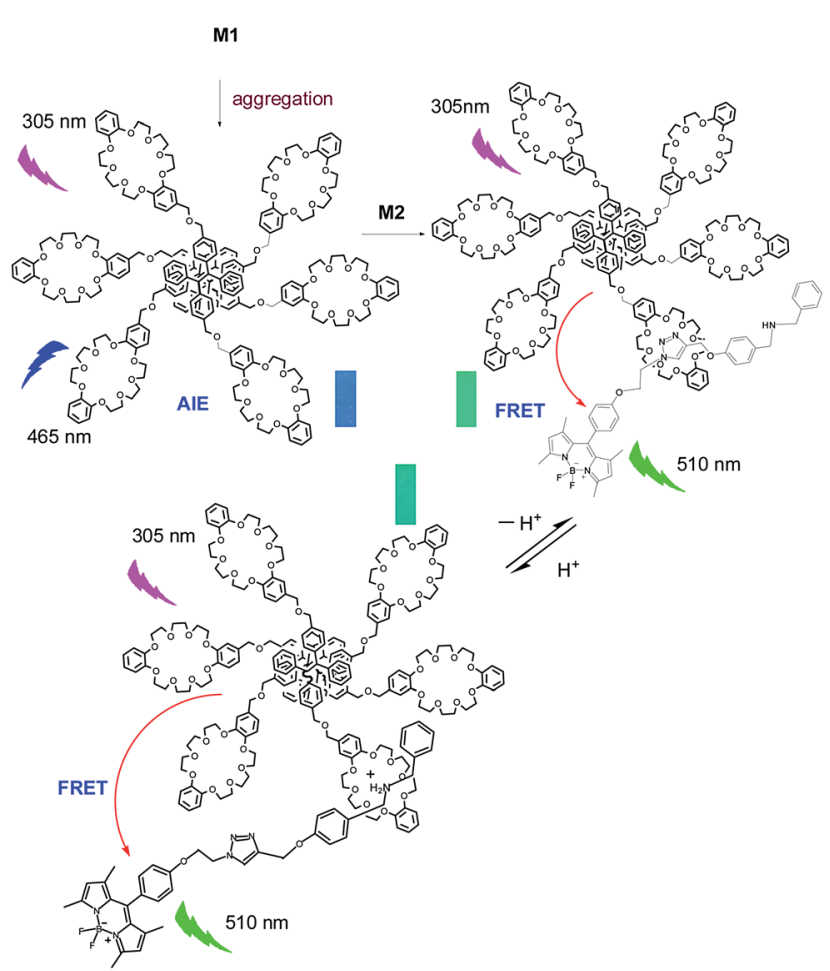

Scheme 2 Proposed interaction mechanism of the host-guest system.

synthesized. The interaction between the donor and acceptor, which act as host and guest respectively, occurred in the poor solution (THF/ $\left.\mathrm{H}_{2} \mathrm{O}, 1: 9, \mathrm{v} / \mathrm{v}\right)$ to generated highly efficient FRET from AIE emission to green emission of BODIPY. The fluorescence titration result shows that this novel FRET system is a $\mathrm{pH}$ stable under acid and base conditions which will undoubtedly shed light on the practical application of FRET system based on host-guest interaction for mimicking the light harvesting system.

\section{Acknowledgements}

We thank the National Natural Science Foundation of China (No. 211571099) and Priority Academic Program Development of Jiangsu Higher Education Institutions (PAPD) for financial support.

\section{Notes and references}

1 B. V. Meer, G. Coker and S. Chen, Resonance Energy Transfer: Theory and Data, VCH, New York, 1994.

2 J. R. Lakowicz, Principles of Fluorescence Spectroscopy, Plenum Publishing Corporation, New York, 2nd edn, 1999.

3 A. A. Deniz, M. Dahan, J. R. Grunwell, T. Ha, A. E. Faulhaber, D. S. Chemla, S. Weiss and P. G. Schultz, Proc. Natl. Acad. Sci. U. S. A., 1999, 96, 3670.

4 S. Weiss, Nat. Struct. Biol., 2000, 7, 724.

5 B. Schuler, E. A. Lipman and W. A. Eaton, Nature, 2002, 419, 743.
6 B. Schuler and W. A. Eaton, Curr. Opin. Struct. Biol., 2008, 18, 16.

7 W. Kühlbrandt and D. N. Wang, Nature, 1991, 350, 130.

8 R. Hildner, D. Brinks, J. B. Nieder, R. J. Cogdell and N. F. van Hulst, Science, 2013, 340, 1448.

9 D. J. Farrell and N. J. Ekins-Daukes, Nat. Photonics, 2009, 3, 373.

10 M. A. Baldo, M. E. Thompson and S. R. Forrest, Nature, 2000, 403, 750.

11 A. Gopi, S. Lingamoorthy, S. Soman, K. Yoosaf, R. Haridas and S. Das, J. Phys. Chem. C, 2016, 120, 26569.

12 I. L. Medintz, A. R. Clapp, H. Mattoussi, E. R. Goldman, B. Fisher and J. M. Mauro, Nat. Mater., 2003, 2, 630.

13 X. Hu, Y. Li, T. Liu, G. Zhang and S. Liu, ACS Appl. Mater. Interfaces, 2015, 7, 15551.

14 L. Yuan, W. Lin, K. Zheng and S. Zhu, Acc. Chem. Res., 2013, 46(7), 1462.

15 X. Han, D. Liu, T. Wang, H. Lu, J. Ma, Q. Chen and H. Gao, ACS Appl. Mater. Interfaces, 2015, 7, 23760.

16 C. G. dos Remedios and P. D. J. Moens, J. Struct. Biol., 1995, $115,175$.

17 X. Hu, A. Damjanovic, T. Ritz and K. Schulten, Proc. Natl. Acad. Sci. U. S. A., 1998, 95, 5935.

18 (a) S. Prathapan, T. E. Johnson and J. S. Lindsey, J. Am. Chem. Soc., 1993, 115, 7519; (b) L. Flamigni, B. Ventura, C. C. You, C. Hippius and F. Würthner, J. Phys. Chem., 2007, 111, 622; (c) M. D. Yilmaz, A. Bozdemir and E. U. Akkaya, Org. Lett., 2006, 8, 2871; (d) C. Hippius, F. Schlosser, M. O. Vysotsky, V. Böhmer and F. Würthner, J. Am. Chem. Soc., 2006, 128, 3870.

19 (a) S.-C. Lo and P. L. Burn, Chem. Rev., 2007, 107, 1097; (b) G. M. Farinola and R. Ragni, Chem. Soc. Rev., 2011, 40, 3467; (c) Y. Tao, C. Yang and J. Qin, Chem. Soc. Rev., 2011, 40, 2943.

20 (a) J.-K. Lee and M. Yang, Mater. Sci. Eng., B, 2011, 176, 1142; (b) Y. Koyama, T. Miki, X.-F. Wang and H. Nagae, Int. J. Mol. Sci., 2009, 10, 4575; (c) A. Hagfeldt, G. Boschloo, L. Sun, L. Kloo and H. Pettersson, Chem. Rev., 2010, 110, 6595; (d) H. R. Li, A. Devaux, A. Z. Ruiz and G. Calzaferri, Nanophotonics, 2006, 6195, G1951; (e) D. Maiti, R. Bhattacharjee, A. Datta and A. Banerjee, J. Phys. Chem. C, 2013, 117, 23178.

21 (a) K. Kikuchi, H. Takakusa and T. Nagano, TrAC, Trends Anal. Chem., 2004, 23, 407; (b) D. Holten, D. F. Bocian and J. S. Lindsey, Acc. Chem. Res., 2001, 35, 57; (c) S. Saha and J. F. Stoddart, Chem. Soc. Rev., 2007, 36, 77; (d) V. Balzani, A. Credi and M. Venturi, Chem.-Eur. J., 2008, 14, 26; (e) C. Chi, M. Chen, D. Liaw, H. Wu, Y. Huang and Y. Tai, ACS Appl. Mater. Interfaces, 2014, 6, 12119.

22 (a) F. D'Souza, P. M. Smith, M. E. Zandler, A. L. McCarty, M. Itou, Y. Araki and O. Ito, J. Am. Chem. Soc., 2004, 126, 7898; (b) E. Maligaspe, N. V. Tkachenko, N. K. Subbaiyan, R. Chitta, M. E. Zandler, H. Lemmetyinen and F. D'Souza, J. Phys. Chem. A, 2009, 113, 8478; (c) O. A. Bozdemir, S. Erbas-Cakmak, O. O. Ekiz, A. Dana and E. U. Akkaya, Angew. Chem., Int. Ed., 2011, 50, 10907; (d) J. Y. Liu, Y. Huang, R. Menting, B. Roder, E. A. Ermilov and 
D. K. Ng, Chem. Commun., 2013, 49, 2998; (e) B. Rybtchinski, L. E. Sinks and M. R. Wasielewski, J. Am. Chem. Soc., 2004, 126, 12268; (f) X. Zhang, Y. Xiao and X. Qian, Org. Lett., 2008, 10, 29.

23 G. Bottari, O. Trukhina, M. Ince and T. Torres, Coord. Chem. Rev., 2012, 256, 2453.

24 (a) Z. Y. Gu, D. S. Guo, M. Sun and Y. Liu, J. Org. Chem., 2010, 75, 3600; (b) R. Menting, J. T. Lau, H. Xu, D. K. Ng, B. Roder and E. A. Ermilov, Chem. Commun., 2012, 48, 4597.

25 L. Meng, D. Li, S. Xiong, X. Hu, L. Wang and G. Li, Chem. Commun., 2015, 51, 4643.

26 (a) F. Loiseau, G. Marzanni, S. Quici, M. T. Indelli and S. Campagna, Chem. Commun., 2003, 286; (b) H. Q. Peng, J. F. Xu, Y. Z. Chen, L. Z. Wu, C. H. Tung and Q. Z. Yang, Chem. Commun., 2014, 50, 1334.

27 (a) J. Mei, N. L. C. Leung, R. T. K. Kwok, J. W. Y. Lam and B. Tang, Chem. Rev., 2015, 115, 11718; (b) J. B. Birks, Photophysics of Aromatic Molecules, Wiley, New York, 1970.

28 J. Luo, Z. Xie, J. W. Y. Lam, L. Cheng, H. Chen, C. Qiu, H. S. Kwok, X. Zhan, Y. Liu, D. Zhu and B. Z. Tang, Chem. Commun., 2001, 1740.

29 (a) W. Z. Yuan, P. Lu, S. M. Chen, J. W. Y. Lam, Z. M. Wang, Y. Liu, H. S. Kwok, Y. G. Ma and B. Z. Tang, Adv. Mater., 2010, 22, 2159; (b) Q. L. Zhao, X. A. Zhang, Q. Wei, J. Wang, X. Y. Shen, A. J. Qin, J. Z. Sun and B. Z. Tang, Chem. Commun., 2012, 48, 11671; (c) A. Ozawa, A. Shimizu,
R. Nishiyabu and Y. Kubo, Chem. Commun., 2015, 51, 118; (d) G. Chen, W. B. Li, T. R. Zhou, Q. Peng, D. Zhai, H. X. Li, W. Z. Yuan, Y. M. Zhang and B. Z. Tang, Adv. Mater., 2015, 27, 4496; (e) Q. Cui, Y. Yang, C. Yao, R. Liu and L. Li, ACS Appl. Mater. Interfaces, 2016, 8, 35578; (f) A. Ozawa, A. Shimizu, R. Nishiyabu and Y. Kubo, Chem. Commun., 2015, 51, 118.

30 (a) G. Ulrich, R. Ziessel and A. Harriman, Angew. Chem., Int. Ed., 2008, 47, 1184; (b) A. Loudet and K. Burgess, Chem. Rev., 2007, 107, 4891.

31 (a) A. Iida and S. Yamaguchi, Chem. Commun., 2009, 21, 3002; (b) H. Langhals, O. Krotz, K. Polborn and P. Mayer, Angew. Chem., Int. Ed., 2005, 44, 2427; (c) T. Qin, G. Zhou, H. Scheiber, R. E. Bauer, M. Baumgarten, C. E. Anson, E. J. W. List and K. Müllen, Angew. Chem., Int. Ed., 2008, 47, 8292; (d) X. Zhu, D. Gindre, N. Mercier, P. Frère and J. M. Nunzi, Adv. Mater., 2003, 15, 906.

32 (a) A. Wakamiya, K. Mori and S. Yamaguchi, Angew. Chem., Int. Ed., 2007, 46, 4273; (b) C. H. Zhao, A. Wakamiya, Y. Inukai and S. Yamaguchi, J. Am. Chem. Soc., 2006, 128, 15934.

33 Z. Xie, B. Yang, F. Li, G. Cheng, L. Liu, G. Yang, H. Xu, L. Ye, M. Hanif, S. Liu, D. Ma and Y. Ma, J. Am. Chem. Soc., 2005, 127, 14152.

34 T. E. Kaiser, H. Wang, V. Stepanenko and F. Wurthner, Angew. Chem., Int. Ed., 2007, 46, 5541. 